Other infectious agents or parameters bound to the rearing conditions may be involved in the occurrence of arthritis in the pig. Only an epidemiologic survey combining the observations made on the farm and at the slaughter house as well as laboratory research might lead to a better understanding of this problem.

\title{
Epidemiology of atrophic rhinitis in pigs : the role of breeding animals
}

\author{
G. MARTINEAU *, A. BROES ** et B. MARTINEAU-DOIZE * \\ " Laboratoire d'Anatomie-Pathologie (Professeur Dewaele), \\ Faculté de Médecine vétérinaire, \\ 45, rue des Vétérinaires, 1070 Bruxelles, Belgique \\ ** Centre provincial de Dépistaye
}

2. Drève du Prophète, 7000 Mons, Belgique

The role of adults in the epidemiology of atrophic rhinitis is still debated.

The purpose of this experiment was to show the asymptomatic carriers of Bordetella bronchiseptica.

The boar introduced into the farm and a sow with her litter were placed in two adjacent pens separed by a grating.

The different classical examinations : (clinical, radiographical, serological and bacteriological) proved to be negative in the boar.

However, the bacteriological examination practised on the alive animal in the ethmoild turbinate allowed to isolate $B$. bronchiseptica. But, this technique requiring a general anesthesia cannot be applied in practice.

As far as the litter was concerned, the bacteriological examinations of the nasal cavities proved to be positive from the 6th week of life.

We confirm the role of the boar in the transmission of the infection. However, lesions developed in the piglets were poor. This might be related with an insufficient infection pressure.

In the absence of insufficient sanitary guarantees in the farm, it is necessary to estimate the risk of introducing an animal from outside into the herd. If a quarantine is applied, it might be advisable to use a contact test. Bacteriological examinations of the nasal cavities of piglets seem to be the most valid test to estimate the dangerous effect of introducing a boar into the herd.

\section{Frequency, intensity and localization of pulmonary lesions in bacon pigs : results of a first series of observations at the slaughter-house}

\author{
F. MADEC et H. DERRIEN \\ Direction de la Qualité, Services vétérinaires \\ Station de Pathologie porcine, B.P. $n^{\prime \prime} 9, F 22440$ Ploufragan
}

Lungs of bacon pigs were systematically examined in five slaughter-houses in Brittany in July 1980. A sample of 2174 pigs was examined. They belonged to a group of 3800 pigs slaughtered during the control period. A total of 68.2 p. 100 of the pigs showed pneumonia lesions and $20 \mathrm{p}$. 100 pleuresy. The cardiac lobes were particularly affected, then the apical, the azygos and the diaphragmatic lobes. The left side of the lung was significantly less affected than the right side. 